\title{
Observed "long-term" temperature change in a midlatitude mesopause region in response to external perturbations
}

\author{
David A. Krueger and C. Y. She \\ Physics Department, Colorado State University, Fort Collins, Colorado 80523, U.S.A. \\ (Received August 4, 1998; Revised November 30, 1998; Accepted November 30, 1998)
}

\begin{abstract}
Analysis of seven years (1990-1997) of measured temperature profiles in the mesopause region (84 to $102 \mathrm{~km})$ at Fort Collins, $\mathrm{CO}\left(41^{\circ} \mathrm{N}, 105^{\circ} \mathrm{W}\right)$, shows that, after removing seasonal variations, there was an episoidic temperature excursion with an amplitude ranging from $7 \mathrm{~K}$ to $14 \mathrm{~K}$. Observable increases began in 1992, maximum temperatures occurred during the first half of 1993, and the excursion was over by about 1996. Since this excursion followed the Mount Pinatubo eruption by a time scale consistent with published model simulations of the effect of stratospheric aerosol on the mesopause region, we attribute the temperature excursion to that eruption. In addition the data is consistent with a background cooling of roughly $1 \mathrm{~K}$ per year, most of which may be attributable to variability in the solar flux. Continued observation towards the coming solar maximum promises to quantify (assess) the "long-term" change in mesopause temperatures resulting from solar variability (anthropogenic effect).
\end{abstract}

\section{Introduction}

The mesopause region $(80-110 \mathrm{~km})$ is an important region of the atmosphere where the diffusion dominated thermosphere couples to the chemistry and dynamics dominated middle atmosphere and troposphere. Direct measurements on the mesopause region were so rare that much of the counter-intuitive thermal structure of this "ignorosphere" was left un-explored. Despite its obvious scientific interests, the study of the mesopause region gained some ground only after its potential application was suggested as modelers (Brasseur and Hitchman, 1988; Roble and Dickinson, 1989; Rind et al., 1990) showed that doubling green house gas, such as $\mathrm{CO}_{2}$, would cause global warming by several degrees in the troposphere and global cooling by $10-20 \mathrm{~K}$ in the mesosphere. Long-term change in the mesopause region then became a significant pursuit from both scientific and societal points of view. In addition to anthropogenic perturbations that are of socio-political interest, natural external perturbations resulting from solar variability and volcanic eruption may in fact be more pronounced making the determination of anthropogenic and biogenic effects much more difficult and the required period of systematic monitoring too long to challenge the patience of laymen and scientists alike. The effects of solar variability and volcanic eruption on temperatures in the mesopause region has been an open question, thus is of scientific interest. Two-dimensional general circulation models (GCM), which include chemistry and gravity wave dynamics, have been developed by Garcia et al. (1984) and Huang and Brasseur (1993), and they predicted that the difference in zonally averaged temperature between solar maximum and solar minimum should be measurable. Although

Copy right (C) The Society of Geomagnetism and Earth, Planetary and Space Sciences (SGEPSS); The Seismological Society of Japan; The Volcanological Society of Japan; The Geodetic Society of Japan; The Japanese Society for Planetary Sciences. temperature increases as high as $3.5 \mathrm{~K}$ were observed in the lower stratosphere (at 20-22 km) in large areas between the equator and $30^{\circ} \mathrm{N}$ (Labitzke and McCormick, 1992) 3 and 4 months after the eruption of Mount Pinatubo (June 15-16, 1991), general wisdom is skeptical of its possible effect in the mesopause region. Like the effect of solar variability, the effect of volcanic eruption on mesopause temperatures has been studied only by a three-dimensional simulation (Rind et al., 1992) up to $90 \mathrm{~km}$; no direct measurements exist to either confirm or reject the result of this simulation.

The introduction of narrowband resonance metal lidars (Fricke and von Zahn, 1985; She et al., 1990), have permitted temperature profile measurements on a regular basis. Enough data have in fact been collected, and seasonal variations and the two-level thermal structure of the mesopause region have been determined on a global basis (She and von Zahn, 1998). The study of the long-term external perturbations on mesopause temperatures requires a much longer record of measurements since it takes more than 11 years to complete a solar cycle. The longest continuous regular observation of temperature profiles in the mesopause region (80$110 \mathrm{~km})$ began in 1991 at Fort Collins, $\mathrm{CO}\left(41^{\circ} \mathrm{N}, 105^{\circ} \mathrm{W}\right)$. Even this data set is still too short for a robust evaluation of these effects. Fortunately, some lidar data were taken in the spring of 1990, and the available data set actually covers a span of 7 years, containing a major volcanic eruption as well as more than half of the solar cycle 22. As such, the data set may be processed to shed light and give hints on the effect of external perturbations in the mesopause region. A first step in this direction has already been taken. Analysis on observed temperatures between 1990 and 1997 at 86 and 100 $\mathrm{km}$ revealed an episodic warming of $\sim 10 \mathrm{~K}$ attributable to Mount Pinatubo eruption (She et al., 1998). The entire data set has now been fully analyzed and the signatures between 84 and $102 \mathrm{~km}$ appear to be clear enough, and both episodic 

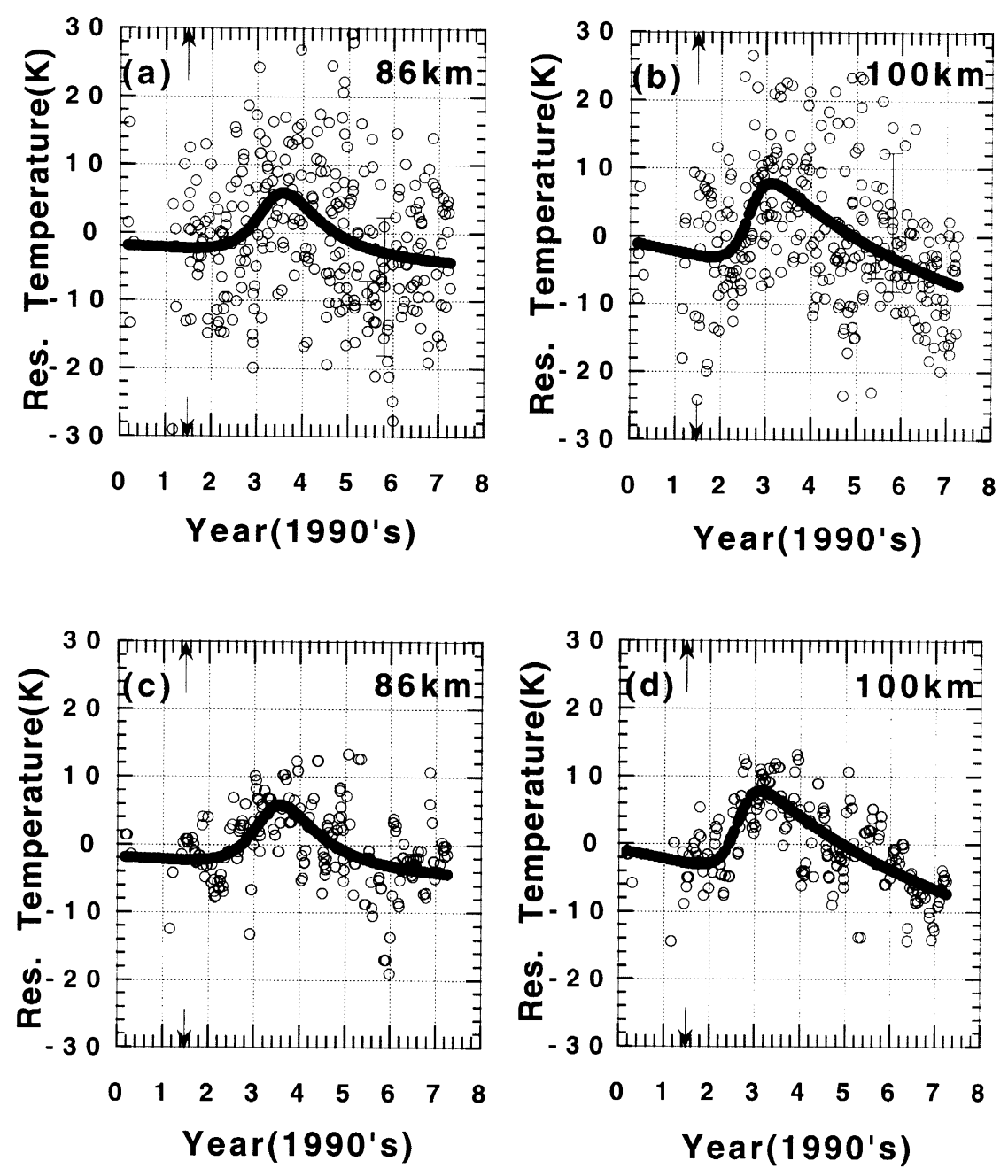

Fig. 1. Time series of residual temperatures between 1990 and 1997 over Fort Collins, $\mathrm{CO}\left(41^{\circ} \mathrm{N}, 105^{\circ} \mathrm{W}\right)$ : (a) at $86 \mathrm{~km}$, (b) at $100 \mathrm{~km}$, along with the associated least squares fits, (c) and (d) 40-day averaged residual temperatures at 86 and $100 \mathrm{~km}$ and the least squares fit to raw data points as in (a) and (b). The time scale is in year, starting January 1, 1990 as zero. The arrows mark the time of Pinatubo eruption.

warming and background cooling can be determined from the data. The purpose of this paper is then to present "longterm" temperature change (covering a span of 7 years) in a midlatitude mesopause region as a function of altitude. To the extent possible, the effects of external perturbations, i.e., volcanic eruption, solar variability and anthropogenic effect, on temperatures in the mesopause region will be delineated and sorted out.

\section{Data and Analysis}

Along with 4 and 5 nights of initial observations, respectively, in springs of 1990 and 1991, quality regular temperature measurements, i.e., on average four to five nights a month with 4 hours or more observation each night, were made over Fort Collins, $\mathrm{CO}\left(41^{\circ} \mathrm{N}, 105^{\circ} \mathrm{W}\right)$ starting May 29 , 1991. A mean temperature profile is computed for each night from vertically smoothed photocount profiles to give a spatial resolution of $3 \mathrm{~km}$ with a typical measurement precision of $\sim 0.6 \mathrm{~K}$ and $\sim 5 \mathrm{~K}$ near the peak $(92 \mathrm{~km})$ and edges $(81 \mathrm{~km}$ and $107 \mathrm{~km}$ ) of the Na layer, respectively. By March 30, 1997, a total of 300 nightly mean temperature profiles were obtained forming a data base covering a seven-year span, from which the time series of temperatures at constant altitudes may be derived for the study of climatic change.

The method of data analysis has been outlined in She et al. (1998). After removing the seasonal variations, the time series of measured temperatures, termed residual temperatures, $T$, at a given altitude are plotted and least-square fitted to the following formula as a function of time, $t$, in years starting from Jan 1, 1990 as:

$$
T(t)=\alpha+\beta t+F(t) ; \quad F(t)=\gamma P(t)
$$

where $\beta$ and $\gamma$ may be interpreted as "long-term" temperature trend and amplitude of an episodic response, respectively. The function, $F(t)=\gamma P(t)$, represents the impact in response to an episodic perturbation during this observation period. Initially, our inclusion of an impact function, $F(t)$, was motivated by the appearance of raw data as shown in Figs. 1(a) and 1(b), respectively for residual temperatures at 86 and $100 \mathrm{~km}$. Likewise, the background cooling term, $\beta t$, was included to obtain a better fit to the data, knowing that a much longer data set is required for an accurate determina- 
tion of the long-term temperature trend, especially during the period containing an episodic perturbation. Although there are many possible choices for the function $P(t)$, we choose the smooth function,

$$
P(t)=2 /\left\{\exp \left[-\left(t-t_{0}\right) / t_{1}\right]+\exp \left[\left(t-t_{0}\right) / t_{2}\right]\right\}
$$

where $P( \pm \infty)=0$, and $P\left(t_{0}\right)=1$. The time constants, $t_{1}$, and $t_{2}$, respectively characterize the rise and decay of the impact. The time and magnitude of maximum episodic change are uniquely determined from the parameters $\gamma, t_{0}$, $t_{1}$, and $t_{2}$. The least-square fitted curves are also shown in Figs. 1(a) and 1(b) together with the data points for 86 and $100 \mathrm{~km}$. As discussed previously (She et al., 1998), the basic credibility of the observed warming lies in the fact that the warming is observable in the raw data of residual temperatures even without any data analysis. Independent of the statistical analysis and assumed form of $P(t)$, added support for the observed warming can be seen in Figs. 1(c) and 1(d), where simple 40-day running averages of the residual temperatures are shown for 86 and $100 \mathrm{~km}$, respectively. The warming episode is clearly seen in these figures and the previous fitting functions (also shown) indeed match the data points very well.

The fitting parameters to data in Fig. 1(a) (Fig. 1(b)) are determined with $1 \sigma$ variability as: $\alpha=-1.8 \pm 2.3(-0.8 \pm$ 2.3) K, $\beta=-0.4 \pm 0.6(-1.4 \pm 0.8) \mathrm{K} / \mathrm{yr}, \gamma=8.2 \pm 2.8$ $(8.3 \pm 1.9) \mathrm{K}, t_{0}=3.3 \pm 0.4(2.7 \pm 0.2) \mathrm{yr}, t_{1}=0.4 \pm 0.3$ $(0.2 \pm 0.1) \mathrm{yr}$, and $t_{2}=0.9 \pm 1.1(2.9 \pm 2.0) \mathrm{yr}$ for $86(100) \mathrm{km}$. The fitted functions are plotted in both Fig. 1(a) (Fig. 1(b)) and Fig. 1(c) (Fig. 1(d)). Note that the $1 \sigma$ variability for several fitting parameters exceeds $50 \%$. The key parameters determining the impact function, $F(t)$, are, fortunately, $\gamma$ and $t_{0}$, which have relatively smaller variability, $\sim 10 \%$ for $t_{0}$ and $\sim 30 \%$ for $\gamma$. We point out that since the variability of fitting parameters are in general cross-correlated, one must make sure that the covariance of the fitting parameters (some of which may be negative) are properly accounted for when evaluating the variability in a dependent quantity or a dependent function in question. The time of maximum response in $F(t), t_{\max }$, and the maximum response, $\Delta T_{\max }=F\left(t_{\max }\right)$, depend only upon $t_{0}, t_{1}, t_{2}$ and $\gamma$ whose $1 \sigma$ variabilities may be used to determine the $1 \sigma$ variabilities in $t_{\max }$ and $\Delta T_{\max }$ in a straight forward manner, giving the values of $\Delta T_{\max }=9.0 \pm 1.7 \mathrm{~K}$ and $12.9 \pm 1.8 \mathrm{~K}$, and $t_{\max }=3.6 \pm 0.2 \mathrm{yr}$ and $3.3 \pm 0.2 \mathrm{yr}$ measured from Jan 1, 1990, respectively at 86 and $100 \mathrm{~km}$.

Time series of residual temperatures at other altitudes have been similarly analyzed and the altitude dependent (residual) temperature change are presented in the following section in terms of altitude-dependent parameters, $\Delta T_{\max }, t_{\max }$ and $\beta$. Their implications on the "long-term" response in temperatures to external perturbations will be discussed.

\section{Results and Discussion}

The time of maximum response, $t_{\max }$, and the maximum temperature response, $\Delta T_{\max }=F\left(t_{\max }\right)$, as a function of altitude between 84 and $102 \mathrm{~km}$ are shown in Fig. 2. Judging from the $1 \sigma$ error bars shown, the determined values for the time of maximum response, $t_{\max }$, and the maximum response,
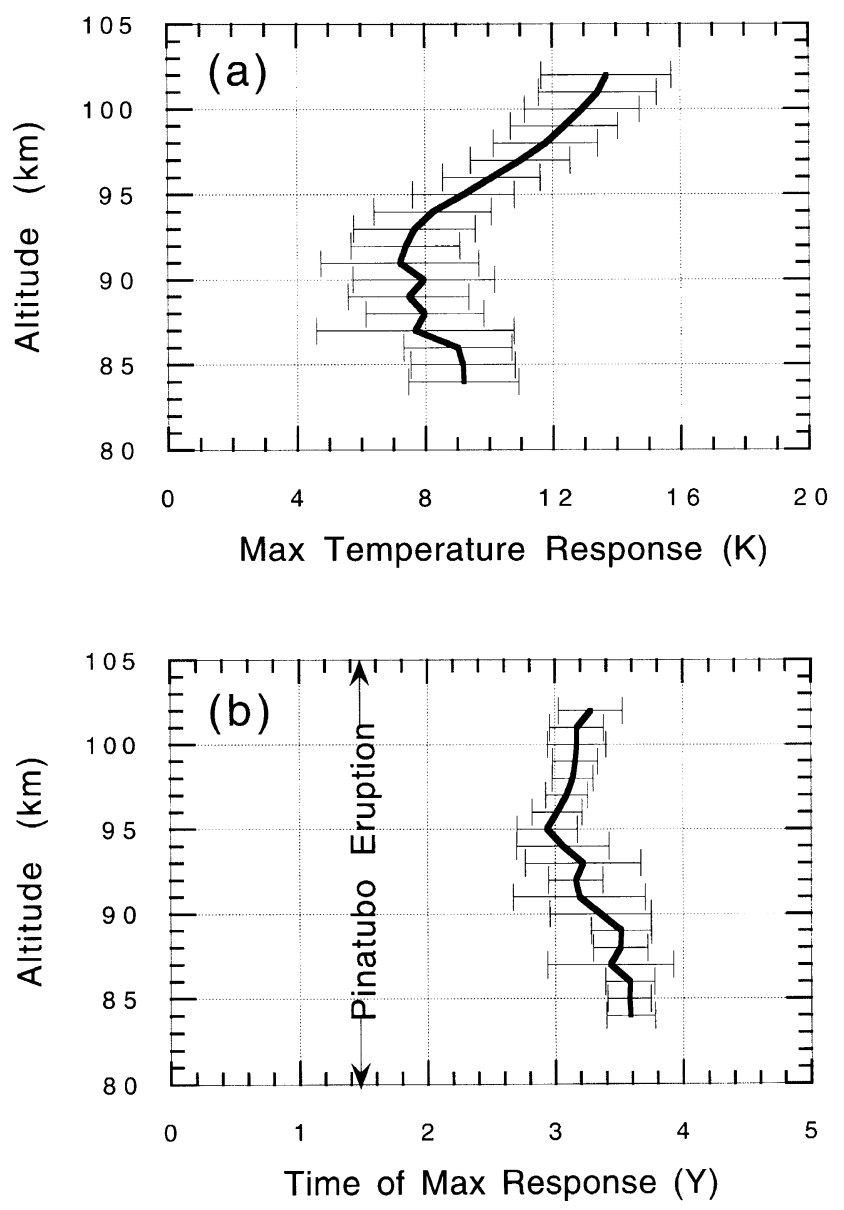

Fig. 2. Altitude dependence of (a) the peak temperature increase, $\Delta T_{\max }$, and (b) the time this occurs, $t_{\max }$, during the observed episodic warming.

or peak temperature increase, $\Delta T_{\max }$, are of considerable statistical significance.

What is the cause of the observed episodic warming in the mesopause region? For a response covering a time scale of several years in this period between 1990 and 1997, the solar flux change and the effect of Mount Pinatubo eruption are two conceivable candidates commonly known that could trigger the observed episode. Figure 3 shows the impact functions at 86 and $100 \mathrm{~km}$ plotted against the time series of the two forcing functions in question: (a) He index, representing solar UV irradiance and (b) total backscattering of stratospheric aerosol as measured by a lidar in Mauna Loa, HA (Barnes and Hofmann, 1997). Since the observed impact function is an impulsive response, it is extremely unlikely that the observed episode of both temperature increase and decrease should be triggered in the same declining phase of solar flux (from 1990 to 1996), and we may rule out the solar cycle effect as the cause for the observed episodic warming. On the other hand, the Mount Pinatubo $\left(15^{\circ} \mathrm{N}, 120^{\circ} \mathrm{E}\right)$ eruption on June 15-16, 1991 caused perturbations not only on global stratospheric ozone and related chemistry (Brasseur and Granier, 1992), but also on atmospheric temperatures (Labitzke and McCormick, 1992) in the tropical lower stratosphere. Such a colossal event occurring before the observed warming as marked by arrows in Figs. 2(b) and 3(b) (at $t \sim 1.45 \mathrm{yr}$ ), 

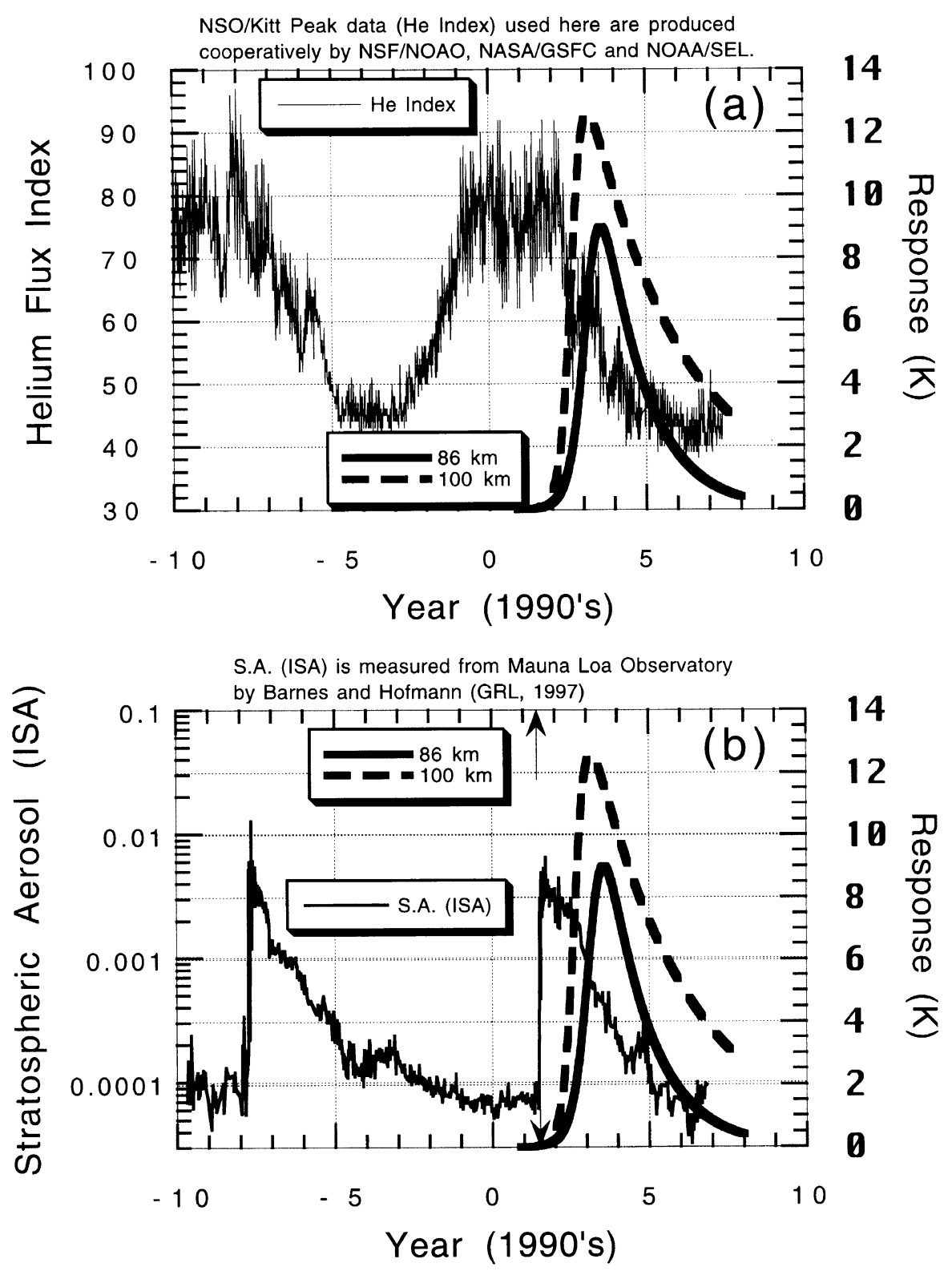

Fig. 3. Impact functions at 86 and $100 \mathrm{~km}$ plotted against the time series of the two forcing functions: (a) He index, representing solar UV irradiance and (b) total backscattering of stratospheric aerosol as measured by a lidar in Mauna Loa.

that have produced a number of documented global changes, may cause temperature changes in the mesopause region as well. The maximum temperature increase, $\Delta T_{\max }$, and its time delay, $t_{\max }$, as shown in Figs. 2(a) and 2(b), are consistent, respectively, with model simulations of the effect of stratospheric aerosol on temperature in (Rind et al., 1992) and of the transport of tropical stratospheric air (Callis et al., 1987) to mesopause region.

According to Rind et al. (1992), the direct radiative heating of the aerosol in the tropical lower stratosphere led to an increase in tropospheric static stability, a weakening of Hadley and Ferrel cell intensities, a reduction in midlatitude westerlies, and an increase in wave energy flux into the stratosphere at subtropical and lower midlatitudes. The additional wave energy intensifies the residual circulation (equator to pole) which led to high-latitude warming and lower latitude cooling in the upper-stratosphere and lower mesosphere. The dynamical effect also led to temperature warming in the upper mesosphere. Three cases allowing zero, modest and full effect of tropospheric cooling to take place, result in a warming in annual mean temperatures at $86 \mathrm{~km}$ and $41^{\circ} \mathrm{N}$ of $1 \mathrm{~K}$, $2 \mathrm{~K}$ and $6 \mathrm{~K}$, respectively. Since the aerosol loading in the model was more in-line with Mount Agung and El Chichon eruptions, a factor of two to three less than that of the Pinatubo eruption, it is reasonable that our observed warming is higher than their prediction. Unfortunately, the top altitude for this simulation was $90 \mathrm{~km}$ and there was no estimate on temperature change between 90 and $102 \mathrm{~km}$. Experimentally, we note a paper (Keckhut et al., 1995) based on Rayleigh lidar data between 1979 and Dec 1993 from a station in South- 
ern France $\left(44^{\circ} \mathrm{N}\right)$ that reported a significant $6 \mathrm{~K}$ warming between 60 and $70 \mathrm{~km}$ in summers 1992 and 1993 relative to temperatures between 1979 and 1991. A recent report from the Czech Republic (Lastoviska et al., 1998) on the enhancement of observed gravity wave activity in 1993 over a comparable six-year (1989-1996) period inferred from radio wave absorption measurements in the lower ionosphere also suggested a Mount Pinatubo connection.

It should be noted, however, the time series used for analysis is based on nightly mean temperatures only and tidal perturbations were not removed. Although models, such as the Thermosphere - Ionosphere - Mesosphere - Electrodynamics General Circulation Model (Roble and Ridley, 1994), predict a dominate semi-diurnal tide in the midlatitude mesopause region, the impact of diurnal tides, in principle, can not be accurately assessed without daytime observation (States and Gardner, 1998). Using our data set, the seasonal climatology of the nighttime tidal perturbation of temperature has recently been analyzed (Williams et al., 1998). When semi-diurnal tides are removed from the nightly mean temperatures, the seven-year time series of the constant term clearly show similar episodic warming. It is extremely unlikely that the minor diurnal tidal components conspired and were phased over the seven year span to produce a warming which peaked in 1993.

It is also interesting that an altitude-dependent cooling rate $\beta$ with reasonable error bars can be extracted from our data. This is shown in Fig. 4, along with the associated variabilities. Also shown as a dashed curve in Fig. 4 is the simulated zonal mean temperature cooling rate in the declining phase of solar flux taken from Huang and Brasseur (1993). Our observed cooling rate (in solid) before the removal of the solar cycle effect may be favorably compared with SME (Solar Mesosphere Explorer) observation, giving $\sim 1.0 \mathrm{~K} / \mathrm{Y}$ at $76 \mathrm{~km}$ at the equator (Clancy and Rusch, 1989), also during a declining phase of solar flux (cycle 21) without considering the solar cycle effect, and with 14 years of Rayleigh lidar observation, giving $\sim 0.4 \mathrm{~K} / \mathrm{Y}$ at $65 \mathrm{~km}$ and $44^{\circ} \mathrm{N}$ (Keckhut et al., 1995) with the solar cycle effect removed. These measured cool-

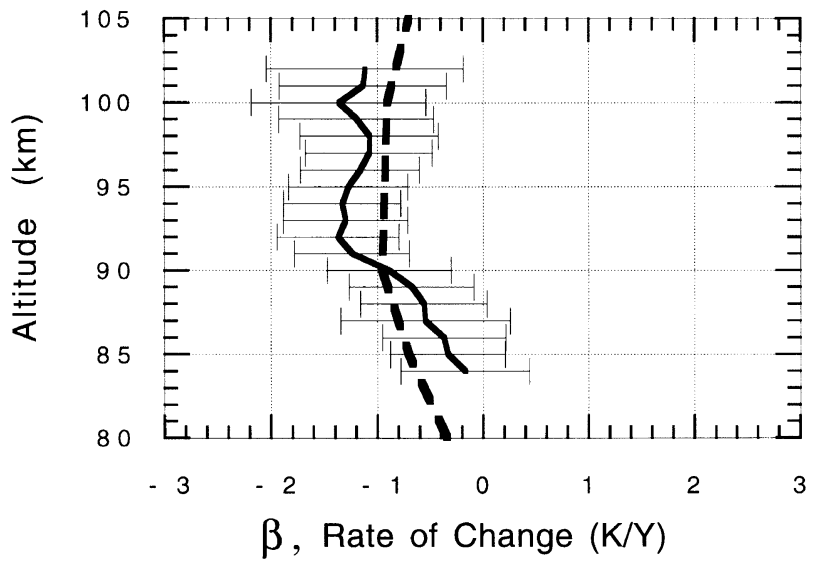

Fig. 4. Observed background cooling rate in the mesopause region between 1990 and March 1997. Also shown in dashed curve is the calculated zonal mean temperature cooling rate in the declining phase of solar flux deduced from simulation (Huang and Brasseur, 1993). ing trends may be compared with the model results (Roble and Dickinson, 1989; Portmann et al., 1995) which predict a 9-10 K cooling resulting from $\mathrm{CO}_{2}$ doubling. Since it takes about a century for atmospheric $\mathrm{CO}_{2}$ to double (Brasseur and Hitchman, 1988), the cooling trends determined from our $\beta$ value are much larger than that could be accounted for by $\mathrm{CO}_{2}$ doubling. Since our observation coincides with the declining cycle of solar flux, most of the observed cooling may be the result of solar variability. Garcia et al. (1984) and Huang and Brasseur (1993) estimated a 6-10 K change between solar maximum and solar minimum, and the simulated cooling rate due to solar variability at $41^{\circ} \mathrm{N}$ is shown in dash in Fig. 4. This suggests that solar variability may be responsible for most of the observed background cooling in the mesopause region. Removing the cooling due to the solar cycle effect leaves one with a much smaller cooling rate that may be due to the global increase of atmospheric green house gases, such as $\mathrm{CO}_{2}$. Since the $1 \sigma$ variability of the measured $\beta$ is large, the above scenario based on our data alone can only be considered as conjecture. Continued observations to complete more than one solar cycle will, however, allow a better assessment on the impact of solar variability on temperatures in the mesopause region. Such a data set may be used to extract the anthropogenic effect from that due to solar variability. Since the temperature change in the rising phase of solar flux presumably will change sign and be opposite to that resulting from increasing $\mathrm{CO}_{2}$, on-going observation towards the coming solar maximum will, presumably, result in a background warming rate. From the difference between the background cooling rate during the declining phase of a solar cycle (say, 22) and the background warming rate during the rising phase of the following solar cycle (say, 23), the residual cooling due to effects other than solar variability may be assessed. Whether this conjecture will turn out to be true and the impact of anthropogenic effects on temperatures in the mesopause region will be resolved, only time can tell.

\section{Conclusion}

A long regular observation on a midlatitude mesopause region over Fort Collins, $\mathrm{CO}\left(40.6^{\circ} \mathrm{N}, 105^{\circ} \mathrm{W}\right)$ gives temperature measurements covering a seven year span from 1990 to 1997. Analysis of this data set revealed an altitude dependent background cooling and an episodic warming between 84 and $102 \mathrm{~km}$. The observed episodic warming which peaks in 1993 is attributable to Mount Pinatubo eruption. Although with marginal statistics at present, most of the background cooling appears to be caused by solar variability. It is suggested that continuing the on-going observation towards the coming solar maximum may permit a delineation between impacts of solar flux and of anthropogenic effect on the "long-term" temperature change in the mesopause region. Our observations have provided clear evidence of temperature change in the mesopause region in response to external perturbations, such as volcanic eruption and solar variability.

Acknowledgments. The authors thank J. R. Yu, M. A. White and $\mathrm{S}$. Chen for their dedication and resourcefulness in performing lidar observations during different time periods. They also thank S. W. Thiel for his contribution to the initial phase of this analysis. The continued support from NSF CEDAR program (ATM 94-15853, ATM 95-10130 and ATM 97-14676) is gratefully acknowledged. 


\section{References}

Barnes, J. E. and D. J. Hofmann, Lidar measurements of stratospheric aerosol over Mauna Loa Observatory, Geophys. Res. Lett., 24, 19231926, 1997.

Brasseur, G. and C. Granier, Mount Pinatubo aerosols, chlorofluorocarbons, and ozone depletion, Science, 257, 1239-1242, 1992.

Brasseur, G. and M. H. Hitchman, Stratospheric response to trace gas perturbations: changes in ozone and temperature distribution, Science, $\mathbf{2 4 0}$, 634-637, 1988.

Callis, L. B., R. E. Bougher, and J. D. Lambeth, The stratosphere: climatologies of the radiative heating and cooling rates and the diabatically diagnosed net circulation fields, J. Geophys. Res., 92, 5585-5607, 1987.

Clancy, R. T. and D. W. Rusch, Climatology and trends of mesospheric (58$90 \mathrm{~km}$ ) temperatures based upon 1982-1986 SME scattering profiles, $J$. Geophys. Res., 94, 3,377-3,393, 1989.

Fricke, K. H. and U. von Zahn, Mesopause temperatures derived from probing the hyperfine structure of the D2 resonance line of sodium by lidar, J. Atmos. Terr. Phys., 47, 499-512, 1985.

Garcia, R. S., S. Solomon, R. G. Roble, and D. W. Rush, Numerical response of the middle atmosphere to the 11-year solar cycle, Planet. Space Sci., 32, 411-423, 1984.

Huang, T. Y. W. and G. P. Brasseur, Effect of long-term solar variability in a two-dimensional interactive model of the middle atmosphere, J. Geophys. Res., 98, 20,413-20,427, 1993.

Keckhut, P., A. Hauchecorne, and M. L. Chanin, Midlatitude long-term variability of the middle atmosphere: Trends and cyclic and episodic changes, J. Geophys. Res., 100, 18,887-18,897, 1995.

Labitzke, K. and M. P. McCormick, Stratospheric temperature increases due to Pinatubo aerosols, Geophys. Res. Lett., 19, 207-210, 1992.

Lastoviska, J., D. Buresova, and J. Boska, Does QBO and the Mt. Pinatubo eruption affect the gravity wave activity in the lower ionosphere?, Studia geopg. et geod., 42, 170-182, 1998.

Portmann, R. W., G. E. Thomas, S. Solomon, and R. R. Garcia, The impor- tance of dynamical feedbacks on doubled $\mathrm{CO}_{2}$-induced changes in the thermal structure of the mesosphere, Geophys. Res. Lett., 22, 1733-1736, 1995.

Rind, D., R. Suozzo, N. K. Balachandran, and M. J. Prather, Climate change and the middle atmosphere: The doubled $\mathrm{CO}_{2}$ climate, J. Atmos. Sci., 47, 475-494, 1990.

Rind, D., N. K. Balachandran, and R. Suozzo, Climate change and the middle atmosphere. Part II: the impact of valcanic aerosols, J. Climate, 5, 189-208, 1992.

Roble, R. G. and R. E. Dickinson, How will changes in carbon dioxide and methane modify the mean structure of the mesosphere and thermosphere?, Geophys. Res. Lett., 16, 1441-1444, 1989.

Roble, R. G. and C. E. Ridley, A thermosphere-ionosphere-mesosphereelectrodynamics general circulation model (TIME-GCM), Geophys. Res. Lett., 21, 417-420, 1994.

She, C. Y. and U. von Zahn, The concept of two-level mesopause: Support through new lidar observation, J. Geophys. Res., 103, 5855-5863, 1998.

She, C. Y., H. Latifi, J. R. Yu, R. J. Alvarez, II, R. E. Bills, and C. S. Gardner, Two-frequency lidar technique for mesospheric Na temperature measurements, Geophys. Res. Lett., 17, 929-932, 1990.

She, C. Y., S. W. Thiel, and D. A. Krueger, Observed episodic warming at 86 and $100 \mathrm{~km}$ between 1990 and 1997: Effects of Mount Pinatubo eruption, Geophys. Res. Lett., 25, 497-500, 1998.

States, R. J. and C. S. Gardner, Influence of the diurnal tide and thermospheric heat sources on the formation of mesospheric inversion layers, Geophys. Res. Lett., 25, 1483-1486, 1998.

Williams, B. P., C. Y. She, and R. G. Roble, Seasonal climatology of the nighttime tidal perturbation of temperature in the midlatitude mesopause region, Geophys. Res. Lett., 25, 3301-3304, 1998.

D. A. Krueger (e-mail: krueger@lamar.colostate.edu) and C. Y. She 